\title{
AN ANALYSIS OF THE THING IS THAT S SENTENCES ${ }^{1}$
}

\author{
Gerald P. Delahunty
}

\begin{abstract}
I refer to the sentences that are the subject of this paper as Thing sentences (TSs), illustrated by The thing is that it's not my phone. These are copular specificational sentences with a definite singular subject and a finite complement clause. Prior research claimed that TSs focus attention on their complement clauses, are pragmatic or discourse markers, indicate a shift in subtopic or topic, communicate that the proposition represented by the complement clause is in "disconformity" with, or problematic in, its context, and that it represents a cause, reason, justification, or grounds for other propositions; these interpretations are claimed to be conventionally associated with the construction. I show that these earlier works are descriptively inaccurate and explanatorily incomplete. While the cause, reason, justification, and grounds interpretations have not been explained, some authors have claimed that the problem interpretation is due to the semantic poverty of thing. I demonstrate that the construction presents the complement proposition as both focused and presupposed and consequently as partially discontinuous with the discourse topic as it has developed up to the point at which the TS is uttered, thereby effecting a shift in the development of the current topic, though never a shift to an unrelated topic. I argue against analyzing TSs as discourse or pragmatic markers and I demonstrate that TSs need not communicate that their complements are problematic, that the range of other interpretations is greater than hitherto proposed, that these are due to the operation of general interpretive schemata, and therefore are not conventionally associated with the construction. I show that the presuppositional effects are due to the minimal semantic specification of thing and the fact that it is definite, and that the focusing effects are due to the predicate position of the clause and to the specificationality of the construction which makes the clause an argument of the subject and thus a marked focus. This analysis of Thing sentences demonstrates that speakers are attuned to the expectations of their audiences and exploit the lexical and syntactic resources of the language to create expression types to manage such things as topical development, and in the case of Thing sentences to signal an unexpected development of the current topic, leading to a change in its trajectory. The analysis shows that at this point in its history, TS interpretations are due to its linguistic features interacting in context with general pragmatic principles.
\end{abstract}

Keywords: Compositionality; Definiteness; Focusing; Presupposition; Specificational construction; Thing; Thing sentence; Topical change; Topic management.

\section{Introduction}

All languages have means to allow speakers/writers to provide clues to their audiences about how to interpret messages. This paper represents a part of a larger research project that investigates the pragmatic and discourse properties of a range of non-canonical

\footnotetext{
${ }^{1}$ My thanks to Andreea Calude and two anonymous reviewers for Pragmatics for their valuable comments on earlier drafts of this paper. Any errors or infelicities that remain are my responsibility.
} 
constructions that make use of semantically minimal lexis and syntactic reorganization to mark information (e.g., inferentials, not that sentences, it-clefts) (Delahunty 2006, 2001, 1997, 1995; Delahunty and Gatzkiewicz 2000; Delahunty and Velazquez-Castillo 2002; Calude and Delahunty 2011a; Pusch 2003, 2006, 2007).

This paper is concerned with a construction I refer to as Thing sentences (TSs), exemplified by:

(1) The thing is that the mouse supplied from the factory is a one-button mouse.

(http://forums.htmlhelp.com/lofiversion/index.php/t655.html)

TSs form a sub-class of specificational copular sentence (Higgins 1976) whose subject is definite (Brenier and Michaelis 2005; Delahunty and Velazquez-Castillo 2002) and whose complement is a finite clause.

In addition to the grammatically and lexically complete version in (1), TSs allow a number of elisions that are associated with factors such as style, register, and mode (Delahunty 2009, 2008, 2011a). The definite article (2), the conjunction (3), or both (4) may be dropped:

(2) Thing is that CDOEXM isn't supported from ASP.NET. . (http://forums.asp.net/t/1219872.aspx)

(3) The thing is, it really can be handy to stay in touch with your email when you're out and about.

(http://www10.nytimes.com/2007/05/24/technology/24pogue.html?)

Thing is, he doesn't want to.

(http://www.sfgate.com/cgi-bin/article.cgi?file=/c/a/2007/05/17SHREK.TMP)

Because their meanings and discourse functions are identical to those of full TSs, I include these variants among the Thing sentences that are the focus of this paper. I will refer to (The) thing is (that) as "the matrix," and the tensed S as "the (complement) clause."

Additionally, the copula may be doubled, e.g., The thing is is that we haven't told John yet (Tuggy 1996: 713). (See also Massam 1999; McConvell 1988). Brenier and Michaelis (2005) offer a compelling optimalization account for the doubling of the copula so I do not address that issue in this paper.

Besides the variants just mentioned, there are related sentence types that differ lexically and syntactically from TSs. The subject head noun may range in semantic specificity from the minimal thing to semantically far richer nouns such as miracle:

(5) The miracle is that the pines survived. ${ }^{2}$

\footnotetext{
2 This is a translation of El milagro es que estos pinos se mantengan from Corpus Oral de Referencia del Español Contemporáneo, included here to show that these sentence types occur cross-linguistically. However, though Spanish has a translation equivalent to an English TS-La cosa es que . . .- the two forms do not function identically in discourse. See Delahunty and Velazquez-Castillo (2002) for discussion of these constructions in Spanish and English. That analysis is similar to Schmid (2000), though we were unaware of his work at the time.
} 
And like TS subjects, these head nouns are typically definite. Schmid (2000) refers to such uses of these nouns as shell nouns. In spite of these similarities, the TSs that I study here function differently in context and require an analysis that differs from that of sentences with semantically richer head-of-matrix-subject nouns. (See Schmid 2000; Delahunty and Velazquez-Castillo 2002.)

A sentence type closely related to TSs has thing as subject head but with premodifiers and/or post-modifiers, e.g., The bizarre thing is . .; the main thing I often wonder is . . . (Newsweek 6/25/2007: 56). ${ }^{3}$ As these differ in their discourse potentials from TSs, I defer their study to a later paper. (See Delahunty and Velazquez-Castillo 2002 for discussion of some of the pre- and post-modifiers that can co-occur with the head.)

Besides variation in the subject, the broader type of these sentences allows variation in the form of the complement. It may be an NP (6), a gerund (7), or a toinfinitive (8):

\author{
The thing is also money. \\ (http://www.ungei.org/infobycountry/247-1214.html) \\ The hardest thing is trying to get them to stop clicking "No" ... \\ (http://news.bbc.co.uk/1/hi/magazine/4156333.stm) \\ The thing is not to be on the receiving end of fate, ... \\ (http://www.hpl.hp,com/news/2002/jan-mar/ramani.html).
}

\footnotetext{
${ }^{3}$ The fragment below shows a very interesting discourse organizing use of sentences whose subjects are headed by thing premodified by ordinals.

"Gen. David Petraeus laid out a plan for Congress," President Bush explained at a press conference last week. "He talked about a strategy ... all aimed at helping this Iraqi government secure its capital so that they can do ... the political work necessary, the hard work necessary, to reconcile."

There are two good things about this strategy, one horrible thing and one thing now seemingly inevitable.

The first good thing is that leaders of both parties agreed that the political objective of the surge - Iraqi reforms aimed at reconciliation - was the correct one. . .

The second good thing about the surge is it will be easy to tell if it is working: . . .

The horrible thing is that an escalating number of U.S. servicemen and women are giving their lives to carry out the surge.

The seemingly inevitable thing is that whether the surge works or not, U.S. forces will begin drawing down in Iraq after this September, ... .

(http://www.creators.com/opinion/terrence-jeffrey/the-coming-consensus-on-iraq.html)
}

The occurrences of the word thing $(s)$ in the second paragraph are what Francis (1994: 84) calls "discourse labels" and are clearly cataphoric in that they prefigure the organization of the following text and connect it with the first paragraph. The occurrences of $\operatorname{thing}(s)$ in the italicized sentences all refer back to their respective thing $(s)$ antecedents in the second paragraph, each one identified by its specific modifier. While the highlighted sentences appear to be TSs with modified subjects, it is clear that they can be paraphrased in ways that TSs cannot: as characteristic or property. These examples demonstrate that the occurrences of thing that are the focus of this paper must be distinguished from similar sentences in which thing is modified. The subject of each of the highlighted sentences has a clear antecedent and must therefore be referential. However, the subjects of TSs have no such antecedent, so their functions must be described and accounted for. 
Because these also differ in semantics and discourse potentials from TSs (e.g., the NP commplement is not propositional and the to-infinitival forms typically have a hortative function lacking in TSs), I do not discuss them here. (See Delahunty 2011a for a brief discussion of some of these types. $)^{4}$

As I define them for the purposes of this paper, Thing sentences would be of interest just because there is as yet no general agreement on either their contextualized interpretations nor on how those interpretations are to be accounted for. However, they are of interest primarily because discovering just what their pragmatic properties and discourse functions are increases our understanding of which properties and functions communicators find so useful to signal that they create a construction specialized for the purpose, as well as of the devices languages select to signal those functions and why those are selected. This paper attempts both to describe how TSs function in context and to explain why they function in those ways by showing how their functions can be derived from their lexico-grammatical characteristics interacting with their contexts and very general interpretive schemata (Carston 2002: 235-242). I show that this can be done without recourse to any ad hoc, construction-specific stipulations. This has implications for the currently active research issues of the fixedness, formulaicity, or grammaticalization of expressions like TS matrixes and such issues as whether TSs are best analyzed as pragmatic or discourse markers, as Aijmer (2007), Carter and McCarthy (2006), and Schmid (2000) claim.

I will argue that the communicative potential of a TS is due to its lexical and syntactic properties, specifically to the definiteness of its subject, the semantic generality of thing, the specificational semantics of the construction, and the predicate position of the complement clause. I will argue that the matrix of a TS is so semantically general that it imposes no specific relationship between the complement clause and its context, unlike similar constructions with semantically richer head nouns. I will also show that the construction designates the complement clause as an argument of the subject and thus as a marked focus, though it is also focused by virtue of being in the predicate of its sentence and thus in the default focus position (Lambrecht 1994). I will argue that because the TS subject is definite, the proposition represented by the clause is backgrounded and its information is anchored in the local discourse, though because it is also focused, this information is also new at the point in the discourse at which it occurs, and as a result, the TS creates a change in the development of the current topic, rather than effecting a complete change of topic, as Aijmer (2007) claims is possible.

\section{Structure of the paper}

The remainder of the paper consists of the following sections: 3. Data sources. 4. Review of prior research. 5. Discourse relevant linguistic characteristics of TSs. 6. What TSs communicate. 7. Other discourse effects of TSs. 8. How TSs do what they do in context. 9. Conclusion.

\footnotetext{
${ }^{4}$ Thing also occurs in a range of other constructions with various discourse effects, for example, OK. Here's the thing (Restasis TV ad), and The thing is this: (Sirr 2009: 34). While Schmid (2000) discusses a number of these types, I discuss them no further in this paper
} 


\section{Data sources}

The data for this study is taken from various corpora, including:

a. the British National Corpus (BNC) of spoken and written English (http://www.natcorp.ox.ac.uk/)

b. the London-Lund corpus of spoken English (LLC) (http://ota.oucs.ox.ac.uk/headers/0168.xml)

c. the Switch Board (SW) corpus of spoken English (http://www.isip.pineconepress.com/projects/switchboard/)

d. the Brown (Brown) family of corpora (http://www.archive.org/details/BrownCorpus)

e. the Corpus of Contemporary American English (COCA) (http://corpus.byu.edu/coca/)

I have also retrieved instances from the internet by directly googling (The) thing is/was (that), by using WebCorp in conjunction with Google (Bergh 2005). Many of my examples are culled from my reading, especially of fiction. The data consists of instances of these sentences along with as much of their context as seemed necessary for their full interpretation, or as much as the concordancers allow. Though I use data retrieved from corpora, I do not consider this a corpus study in the strict sense. My purpose is to develop a general account of the discourse properties of the TS form and so I do not distinguish amongst TSs from various genres and registers. The corpora were merely sources of authentic data.

\section{Review of prior research}

Much of the research on TSs has focused on the double copula variant and there is relatively little on the pragmatic/discourse properties of TSs per se. However, remarks in Biber et al. (1999), Miller and Weinert (1998), Carter and McCarthy (2006), Tuggy (1996), Aijmer (2007), and Schmid (2000) are helpful in initiating the discussion.

\subsection{Biber et al. (1999)}

Biber at al. characterize the matrix of a TS as a four-word lexical bundle (p. 1006) which functions as an "overture," that is, "a longer expression from a stock of readymade utterance openers," and thus a subtype of "preface" or "utterance launcher" (pp. 1073-1076), which are elements in the grammar of conversation (pp. 1037-1125). ${ }^{5}$

\footnotetext{
${ }^{5}$ This characterization locates TSs as primarily a spoken form and as a device that can be used to re-direct a discourse topic. Other researchers make similar claims about the discourse distribution of TSs, as well as claims like that of Biber et al. that the TS matrix is "ready-made" on all occasions of use, which I believe is too strong: there is no evidence to support the claim that full TS matrixes in edited text are ready made. A better characterization of the discourse distribution of TSs would be as a form that occurs primarily in unplanned, time-constrained, unedited, on-line production, or simulations thereof, e.g., in
} 
Overtures are a more explicit way of signaling a new direction in the conversation, though nothing specific is said about the roles of TSs per se. Nor are we given any details about the specific effects TSs have on the direction of a conversation, nor reasons for why they are thus used.

\subsection{Miller and Weinert (1998)}

Miller and Weinert characterize (the) thing is as a "semi-fixed construction" (p. 197),

which can be used to concentrate the listener's attention either on properties or on propositions. An example of a proposition is given in (69) [Miller and Weinert's numbering].

(69) A What about Edinburgh do the people go up there

B oh yeah a lot

$\mathrm{C}$ oh aye especially at night they go to the pictures but the thing is if you go to the pictures if you go to the late show you're you've to run for buses (p. 243)

Miller and Weinert provide no explanation for why TSs function as they do, and they provide no more detailed description of TS functions than that they "concentrate the listener's attention either on properties or on propositions." We would like to know how TSs have this effect and what pragmatic and discourse effects derive from this concentration of attention, e.g., what constraints TSs impose on the discourse roles of its proposition that differ from those that would be associated with the unembedded clause (the unmarked version of a TS). We would also like to know whether the attentionconcentrating effects of TSs are different from those of other constructions that could also be argued to concentrate attention on a proposition, for example, inferentials such as It's (not) that it was raining (Delahunty 1995, 2001; Pusch 2003, 2006, 2007). We would also like to know how TSs accomplish their discourse effects. (See discussion of Schmid 2000 below.)

fictional dialog, but which does occur elsewhere, though less frequently, and only rarely in academic prose. (Delahunty 2011a.)

${ }^{6}$ Miller and Weinert give no further context, and indeed many authors (e.g., Carter and McCarthy, Aijmer, Tuggy, Schmid) give so little co-text with their examples that it is often impossible to say with certainty how the target utterance/sentence is (intended) to be interpreted. The examples I cite in the current paper are embedded in enough co-text to allow readers to judge for themselves how they are to be interpreted, and I adopt an aspect of Conversation Analysis methodology by selecting wherever possible examples whose co-text provides indications of how the target example is to be interpreted, such as an interlocutor's response to it and its producer's ratification of that response. Examples taken from fictional dialog are especially useful in this regard.

${ }^{7}$ Miller and Weinert add: "This example is . . typical of our data in that the thing is is never followed by a complementizer, there is regularly a pause between it and the next clause, which has its own pitch contour. These properties are compatible with a loose construction in which the thing is and you've to run for buses are juxtaposed ..." (p. 243; emphasis in original). None of my data suggest that the spoken TSs, which are characteristically, though not always, manifested in the ways described here, ostensively communicate anything different from their full versions. However, what these characteristics indicate is the subject of separate papers (Delahunty 2009, 2011b). 


\subsection{Carter and McCarthy (2006)}

According to Carter and McCarthy (p. 148):

The phrase the thing is is frequent in spoken English and functions as a discourse marker which focuses attention on what follows and usually signals that there is a problem. The verb form $i s$ tends to be stressed. The is commonly ellipted in informal use:

The thing is ... erm ... we don't have any money left. Yeah, but, you know, thing is, she's left it rather late.

Carter and McCarthy define discourse markers as "words and phrases which function to link segments of the discourse to one another in ways which reflect choices of monitoring, organization and management exercised by the speaker" (p. 208). As such, they are a subclass of pragmatic markers, "which operate outside the structural limits of the clause and which encode speakers' intentions and interpersonal meanings" (p. 208).

Carter and McCarthy agree with Miller and Weinert in claiming that the TS matrix focuses attention on the complement clause, but add that this focus usually signals that there is a problem, presumably represented by the clause in relation to its context. However, no analysis of the construction is given, nor is any explanation provided for how and when it "signals that there is a problem," nor how these functions are related to those of discourse markers. I will show that the interpretation signaled by Thing sentences is more general than just that there is a problem, but more constrained than merely focusing/concentrating hearers' attention on a proposition. I will also argue that rather than "linking segments of discourse to one another," TSs actually separate their clauses from their prior discourse contexts. ${ }^{8}$

\subsection{Tuggy (1996)}

Tuggy deals primarily with the conditions that license the double-is construction, but he also argues that TSs belong to a class of expressions he labels "focus formulas" (FFs) (p. 724) and that these communicate "Hey! Pay attention to this!" (p. 725), and that this message supersedes their compositional meaning (p. 725). I assume that it is the compositional meaning of the matrix that is superseded, though it is not clear whether the attention-directing effect is in addition to the compositional meaning of the matrix, or whether it completely overrides and replaces that meaning and is therefore arbitrarily associated with the form with no dependence on its lexis, syntax, and semantics. This latter interpretation is consistent with his remark that:

${ }^{8}$ Carter and McCarthy remark on the frequency with which TSs occur in spoken English, and Tuggy and Miller and Weinert are concerned only with spoken TSs. None explain this discourse distribution, which I address in Delahunty (2011a). 
There is a gradation of FF-hood, which tends to correlate inversely with the amount of information included in the FF. The thing (about it) is is about as pure an FF as there is: its only function is to focus attention on the following clause. It means 'Hey!' and little or nothing else (p. 725).

Tuggy provides us with no explanation for how or why TSs focus attention on their clauses, though it follows from Lambrecht's (1994) claim that the predicate position is the default focus position, and thus requires no construction-specific stipulation. However, if we take Tuggy's paraphrase literally (and as he has given us no reason to do otherwise, we must) and substitute his "Hey! Pay attention to this!" for the TS matrix, we get pretty odd results. Compare the TS from Miller and Weinert quoted above with:

(9) oh aye especially at night they go to the pictures but Hey! Pay attention to this! If you go to the pictures if you go to the late show you're you've to run for buses

The original and adapted texts are not at all discourse-equivalent. It is hard to imagine a context that would license such an elaborate and explicit demand for attention as a continuation of the prior utterance. Even if we paraphrase the TS matrix merely as Hey! we license incorrect predictions, such as that the TS should, like Hey! be able to cut off a current topic and introduce a completely new one:
A: Beautiful weather we're having.
B: Hey! The bus is coming.
B': ???The thing is, the bus is coming.

Even if we substitute other attention-directing expressions, such as Guess what! Listen to this, or Look out! the texts are not discourse-equivalent:

(11) oh aye especially at night they go to the pictures but guess what/listen to this/look out, if you go to the pictures if you go to the late show you're you've to run for buses

So, paraphrasing the discourse meaning of TSs as Hey! Pay attention to this! is incorrect.

Additionally, Tuggy says (p. 722) that thing in a TS construction,

means something like 'noteworthy thing'; and 'noteworthy' would have to mean 'in disconformity with something normal/established/ backgrounded,'

though he does not specify how this interpretation comes about, only that it is based on the "semantic schematicity of thing" (p. 722). Tuggy does not explain how the schematicity of thing licenses its "noteworthiness," nor how or why noteworthiness has to be interpreted as "in disconformity." In fact, this interpretation suggests that TSs have the same discourse functions as but, which can also be interpreted as in disconformity, though they are not always interchangeable:

(12) A: Is the Department Chair in?

B: She's in, but you can't see her now. 
B': ???She's in; the thing is you can't see her now.

Nor does he explain how that normal "something" is selected and related to the focused clause, nor how disconformity might underlie the range of specific interpretations associated with TSs. Below I provide a more accurate description of TS interpretations and a theoretical basis for them.

\subsection{Aijmer (2007)}

According to Aijmer (pp. 43):

Thing is has the form and function of a pragmatic marker. Like other markers it situates the utterance in relation to other utterances in the discourse. In (28) [her numbering], it signals a new (sub)topic:

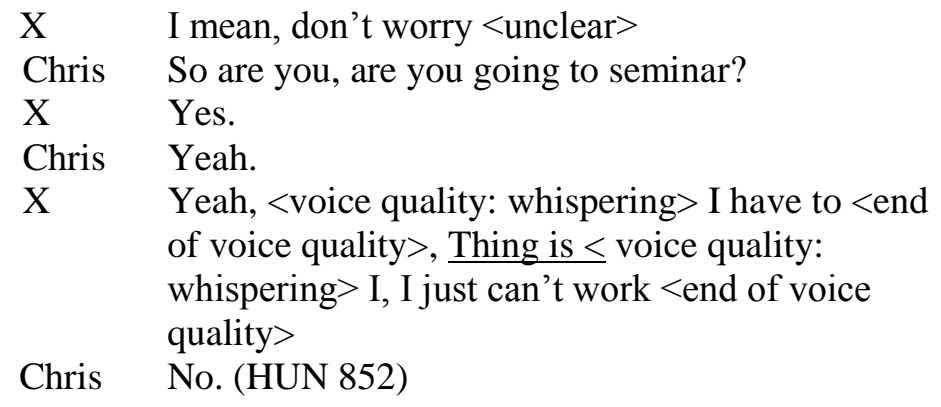

My data are consistent with the claim that TSs signal a shift in the current topic, but not with the claim that they can signal a shift to a new topic. Unfortunately, we cannot tell which is signaled by the TS in Aijmer's (28) because we have such little context.

She continues (p. 43):

The thing is that has conventionalized the rhetorical meaning of explanation or justification for a point of view (cause, ground for an opinion expressed in the preceding context) [her (29) and emphasis]:

(29) MH Occasionally I see something that you've missed and think that it's a lot better than you do. The thing is that you can't always judge your own work, this is the value of working together. (CCO 339)

If a form has conventionalized a meaning we should expect to find that meaning in all of the form's occurrences. However, we find occurrences of TSs in which the order of justification and justified, etc. is the reverse of what Aijmer claims:

(13) I want to believe he is truly sorry and that it won't happen again. I am willing to give this a second chance because I do believe it was a one time thing and that the guilt has eat him alive and that is why it was so hard for him to work on our marriage. The thing is that I don't want to be the fool again. I don't believe it meant much to him but of course the thought kills me and breaks my heart.

(Divorce Support. Why do Spouses Cheat?

http://divorcesupport.about.com/od/cheatingspouse/a/cheatingstory $16 . \mathrm{htm}$ ) 
This TS appears to address an inference that an audience could potentially derive from the prior co-text, viz., that the speaker's belief and willingness are likely to lead to her being made a fool of again. That is, the text before the TS provides the grounds for the opinion expressed in the TS, not, as Aijmer claims, the other way round. Note also that this TS effects the subtopical shift from what the speaker wants and believes to what she does not want and believe.

We also find occurrences of TSs which communicate explanations or accounts for what can be inferred from them, even though this inference is left implicit:

(14) A: Well, can I have this [phone call] transferred upstairs?

$\mathrm{B}$ : Well, the thing is that it's not my phone you're calling from.

A: OK (London-Lund Corpus; mark-ups omitted)

In this example, B's response provides a premise from which A can infer that B cannot transfer the phone call upstairs, an inference that is not overtly expressed. And contrary to Aijmer's claim, this TS does not provide grounds for what precedes it, viz., A's question.

As I show in section 6.5 below, cause/reason and problem interpretations are not always associated with TSs, so they cannot, contrary to Aijmer's claim, be part of their conventional meaning. In which case, they must arise from general processes of interpreting utterances in context and must therefore be due to the interaction of the linguistic form of the utterance, its context, and general pragmatic principles.

Aijmer also claims that [her (30) and emphasis] (p. 44):

When 'the thing is' has epistemic meaning it can combine with but to express opposition or rejection:

(30) But the thing is that it seems that we're a cultural the way the system is set up (HUJ 364)

However, Aijmer provides no context for this example. It is especially puzzling that she provides no prior context for it, as she claims a special relation between TSs and their preceding contexts. So, it is impossible to know what, if anything, is being opposed or rejected in her (30). Also, one of the major functions of but is to communicate that its associated proposition is counter to some contextually licensed expectation (Blakemore 1989 and references therein), so it's impossible to tease apart the contributions of but and the TS in Aijmer's (30). More importantly, TSs can express opposition or rejection or contradiction without the help of but:

(15) "You never talk much about your army days," Siobhan said.

... (99 words omitted)

"Want me to repeat the question?"

“Thing is, Siobhan, it wasn't a question." (Rankin 2003: 301)

although the TS format is not required here to reject the presupposition communicated by Siobhan:

(15') "Want me to repeat the question?"

"Siobhan, it wasn't a question." 
Aijmer also claims that [her (31) and emphasis] (p. 44):

The phrase can be used rhetorically to add a new argument:

(31) And the thing is that when of the, I haven't seen anywhere any kind of poll system, you know, I think it's a, I've always thought it outrageous as a woman actually, that women have had to pay for toilets, <unclear> and erm, I mean if we, you know, if we, we might, I mean, I, I would be in favour of a system where, you know, you, say a local Council issues a pass, which you pay for, have differential rates, but it's like people paying up front for that toilet service. (D95684)

Here again, Aijmer offers no prior context to which to relate the TS, though presumably the TS in her (31) is conjoined to whatever the prior context was by and, one of whose major functions is to add whatever it is associated with to whatever occurred before it, including, one must assume, arguments. So, and without the TS would be sufficient to add a new argument, though TSs without and can add arguments too, as in:

(16) So what am I doing? Handwriting? You must be joking. After ten years of word processing I can't even do handwriting anymore. I know I ought to be able to: handwriting is supposed to be one of those like using chopsticks, once you get the hang of it, it never really deserts you. The thing is that I've had much more practice with chopsticks than pens, so no, I'm not handwriting.

(DNA/The Little Computer that Could. http://www.douglasadams.com/dna/98070702-a.html)

In this fragment, amongst other functions, the highlighted TS adds a new argument to the ongoing litany of arguments for why the author is not handwriting; however, new arguments can be added without any special marking such as a TS matrix, as the fourth sentence ("After ten years ...") of (16) shows. So, the TS format is not necessary to signal a new argument as any additional information may be so construed if appropriate in the context.

Aijmer concludes this section of her paper with:

To sum up, to every pre-fabricated unit which is licensed by the collocational framework there is a description of what meaning it performs in the interaction. New meanings emerge in the interaction starting out as ad hoc implicatures. ${ }^{9}$ Some implicatures can become conventionalized because they are frequent and useful for particular purposes. As a result we can explain that 'the fact is that $X$ ' although meaning what it actually says can also have the dialogic meaning of rejection (disclaiming) or can be used to strengthen a position (proclaiming) or elaborate on it for argumentative

${ }^{9}$ I don't know what Aijmer has in mind by "ad hoc implicatures" as my understanding of implicatures is that they are either conventional and due to the semantics of their triggers (e.g., those licensed by but) or are conversational and licensed by the interactions among the semantics of the utterance, its relevant context, and general pragmatic principles. An avenue of inquiry that I do not follow in this paper is whether the discourse uses of words such as thing, fact, etc., might be amenable to the $a d$ hoc concept formation processes proposed in the relevance theory literature (see esp. Carston 2002, ch. 5). 
purposes. The more routinised phrases (most typically 'thing is') are the most expendable and have primarily textual function (p. 44).

While Aijmer's explanation for the discourse meanings of The fact is that $X$ is grounded in the semantics of fact, she provides no corresponding account for the discourse functions she attributes to TSs, beyond suggesting that they begin as ad hoc implicatures. Nor does she describe how the functions she ascribes to TSs - pragmatic marker indicating a new (sub)topic, rejecting something in the context, and adding a new argument - are related.

One must ask why TSs license the particular ad hoc implicatures Aijmer claims and not others? Certainly, explanation/justification are "frequent and useful for particular purposes," but why are they conventionally associated with TSs? My data are consistent with Aijmer's claim that a TS may be used to communicate that the proposition represented by its clause provides an explanation or justification for another proposition derivable from the local context. However, the TS form is certainly not necessary to trigger this interpretation, as considerable research on juxtaposed utterances shows (see particularly Carston 2002 and references therein); for example:

A: Frieda has made two trips to Boulder this week.

B: Chomsky gave two lectures at CU.

B's utterance can readily be interpreted as an explanation for Frieda's trips. The interpretation of this exchange as 'state-of-affairs/explanation for the state-of-affairs' is a function of general interpretive schemata.

\subsection{Schmid (2000)}

Schmid claims that the uses of thing with which we are concerned here should be included among the uses of shell nouns, a class of uses of abstract nouns with which a speaker can:

a. "characterize and perspectivize complex chunks of information"

b. "encapsulate these complex chunks of information in temporary nominal concepts with apparently rigid and clear-cut conceptual boundaries"

c. link "these nominal concepts with clauses or other pieces of text which contain the actual details of information, thereby instructing the hearer to interpret different sections of text together" (p. 14)

These roles may be linguistically realized in one or both of two ways, which he takes to be diagnostic of shell nouns [Schmid's numbering]:

(1.1) (a) Determiner $+($ Premodifier $)+$ Noun + postnominal that clause, $w$ h-clause or to-infinitive

(b) Determiner $+($ Premodifier $)+$ Noun $+b e+$ complementing that-clause, $w h$ clause or to-infinitive (p. 3)

TSs fit Schmid's pattern (1.1.b) but not pattern (1.1.a): that-clauses after thing in pattern (1.1.a) seem to be impossible or to have to be relative clauses: 
*The thing that it's not my phone you're calling from is ...

Schmid (p. 27) characterizes pattern (1.1.b) as an equative construction consisting of an IDENTIFIED subject and IDENTIFIER complement linked by an identifying relation suggesting that the IDENTIFIED and IDENTIFIER are identical. He glosses this relation as "experiential identity," which "[i]n plain terms, . . . means that two or more separate linguistic elements contribute to the formation of one thought" (p. 29). Unfortunately, these terms are not as plain as Schmid appears to think. At the very least, "thought" is undefined and so we do not know how to distinguish one thought from two or more, nor a full thought from a partial one, nor how the linguistic elements of the utterance contribute to thought formation. Schmid characterizes identity as "the notion that the shell noun and shell content [i.e., complement clause] express ideas about the same thing" (p. 27), which is also rather vague and imprecise.

Elsewhere he further characterizes the relation between shell nouns and their complements, saying:

For shell nouns to be able to function as containers it is necessary that they have a gap, a hole, or some other kind of opening or dent which can receive the content. Likewise, if a noun is to function as a shell noun, its semantic structure must include one of several gaps that can be filled by the information given in the shell content (p. 76).

Again, this is very metaphorical and imprecise, though Schmid elsewhere characterizes the shell use of reason as a two-place relation, a characterization similar to Fraser's (2005) definition of a discourse marker as an expression imposing a two place relation between the expression it is in construction with and elements of its context. I show below that Schmid's (1.1.b) realization of shell nouns is a specificational construction in which the subject represents a variable and the complement its value. This wellunderstood construction captures the relationship between a shell noun (phrase) and its shell noun contents, without recourse to the kinds of stipulation and metaphor Schmid employs.

Schmid (p. 4) divides shell noun uses into six broad categories - factual, linguistic, mental, modal, eventive, and circumstantial, each with several subcategories. He categorizes thing as a factual shell noun, along with fact, point, problem, reason, difference, and upshot. Factual shell nouns are used "to create conceptual shells for 'abstract' states of affairs and facts. Any experience, with the exception of first-order entities, can be construed as a fact by means of an appropriate shell-content construction" (p. 92). Though he does not define "factual," I assume that he means something like 'warranted true and known to be so.' As a factual noun, thing has "neutral uses," along with fact, point, case, business, phenomenon (pp. 93-101); reason uses along with reason, cause, ground (pp. 102-106); and attitudinal, specifically problem, uses, along with point, problem, trouble, difficulty, snag, etc. (pp.120-125).

Regarding the following neutral uses of TSs [Schmid's numbering and emphases] (p. 94):

(7.2) (a) you're 61 now and it's time you settled down. "The thing is that he needs a lot of loving. (SPOKEN) 
(b) I'm not a doppelganger for Robert Redford. "The thing is he just doesn't care. $\left(\right.$ SPOKEN) ${ }^{10}$

Schmid says (p. 94):

By shelling ideas ... . with the collocation the thing is (that), speakers achieve three things. Firstly, they turn ideas or possible facts into facts.

Schmid does not specify just how this interpretation is related to or, better, derived from, the linguistic features of the construction.

He continues (p. 94):

Secondly, they add evaluations to these facts. Although it is often difficult to pinpoint their precise linguistic trigger, negative evaluations seem to predominate and therefore the description as 'a problem' ... . is probably justified.

Schmid appeals to Tuggy's claim that TSs indicate "disconformity with something normal/established/backgrounded," which, as we've seen, is itself unexplained.

He adds (p. 94):

And third, speakers imply that both the fact itself and its evaluation are of concern to both the speaker and the hearer(s) and that this is the reason why the fact is mentioned in the first place.

And (pp. 94-95):

In many instances, the emphasis is partly motivated by a contrastive or counterexpectational relation to what has been said before by one of the discourse participants. This does not seem to be the case in (7.2), however. The full paraphrase for the second sentence in example (7.2a) would then be something like (7.2a') [Schmid's numbering]:

(7.2a') It is a fact that he needs a lot of loving, and this concerns both you andme, and therefore I am telling you about it.

Because general pragmatic theories, e.g., relevance theory (Sperber and Wilson 1995), posit that any utterance and its evaluation will be presented as being of concern to both speaker and hearer - why else would a speaker undertake the burden of creating the utterance and the hearer undertake the burden of interpreting it - no stipulation of this kind is required for the analysis of TSs, and no special form is required to imply it.

Schmid continues (p. 94):

The third aspect, then, can be interpreted as an emphatic linguistic gesture intended to stress the relevance of what one says and to invest it with more significance and importance [presumably than the unmarked counterpart of the TS - GPD].

\footnotetext{
${ }^{10}$ Because Schmid provides so little context, I cannot interpret these two TSs sufficiently to be able to characterize their discourse functions at all.
} 
This is very like Miller and Weinert's, Carter and McCarthy's, and Tuggy's claims that a TS focuses attention on its complement clause.

Schmid claims that in addition to its neutral uses, thing also has causal, and specifically, reason uses, which he glosses as, "causality is a relation between two events or facts, in which one entity, the CAUSE, is conceived by the human conceptualizer as being prior to, contributing to and/or being responsible for the occurrence or existence of another, called EFFECT" (p. 102). In TSs, "the that-clause represents the CAUSE component" (p. 106), though as we will see, TS clauses represent more relations than merely causal ones.

Schmid claims that these CAUSE interpretations derive from the semantics of various shell nouns by triggering the construction of cognitive frames which include gaps into which ideas, including that represented by the noun's complement clause and one or more derived from the context are inserted. Schmid illustrates this process with the noun reason (p. 76).

As is typical of shell nouns, the noun reason itself provides information of a very limited nature. It does convey the information that one thing is causing or has caused some other thing but it gives no clue as to what those things are. By evoking a two place relation between cause and effect, the noun reason sets up two clearly defined semantic gaps which need to be filled. . .

Generalizing from this example, it can be claimed that there are specific semantic gaps inherent in the meaning of all shell nouns. (Emphases added.)

However, because of the minimal semantics of thing, it cannot prompt the creation of such a frame and thus must function differently from semantically richer shell nouns. (See Delahunty and Velazquez-Castillo 2002 where this idea was independently proposed.) It merely puts "extra focus" (p. 333) on its complement. This extra focus derives from four sources (p. 333-4):

a. Speakers' desire to "highlight a piece of information for attention simply because they feel it is particularly important" (p. 333).

Of course, this does not explain why speakers choose TSs amongst the various devices that highlight information, e.g., inferentials.

b. "What the speaker says is in contrast to what has been said before or what is believed by the hearer(s). This is a special variant of the emphatic focus, which can be called contrastive focus [emphasis in original]. The element of contrastiveness is captured in Tuggy's (1996) paraphrases by the notion of disconformity" (p. 333).

I critiqued this idea above and I account for it below as deriving primarily from the fact that the TS clause is doubly focused.

c. "The hidden evaluative connotations which, as discussed in [Schmid's] Section 7.2, can often be detected in the uses of the thing/point is that can play a role" (sic) (p. $333)$.

Elsewhere Schmid glosses these evaluations as "problem": 
d. "Speakers may simply use the pattern in order to gain time for the formation of their ideas and the translation of these into language. As has been shown in (16.4) and (16.4'), the thing is that and the point is that leave a wide range of ways of continuing and completing the sentence, and are therefore versatile enough to function as hesitators" (p. 334).

None of my data seems unambiguously to serve this function, and its proponents would have to demonstrate that TSs so used have no other function and would also have to explain why speakers might choose the relatively complex TS form for this function rather than much simpler forms that can be more convincingly shown to so function. I do not deal further with this issue in this paper.

Schmid's explanation for how TSs focus their clause and for how they differ from similar constructions with other shell nouns is:

Thing, point, and question make up a separate group of focus constructions because only these three nouns are semantically so general that they are truly redundant from a propositional point of view. The uses of this first type are therefore only of a focusing character. This is different with the second type of uses of the pattern N-be-cl, in which a much greater range of nouns can be found. These nouns are semantically specific enough to add a characterization to the shell-content complex (p. 334).

Schmid argues that TSs belong to one of his two uses of shell nouns, specifically that they are identificational sentences whose basic interpretation is factual, to which may be added causal and negative connotations. He provides no explanation for why thing is factual, nor how the causal and negative interpretations arise, other than to reference Tuggy's disconformity proposal, whose association with TSs is also unexplained. Nor does he discuss the discourse circumstances under which these additional meanings arise. He does not include TSs in any of his other meaning categories, for example, in his SOLUTION group (pp. 219-20), the complement of the PROBLEM suite of interpretations; as we'll see below, we find TSs whose interpretation appears to be quite the opposite of PROBLEM. ${ }^{11}$

\subsection{Are TSs pragmatic or discourse markers?}

Because several of the authors cited above categorize TSs as pragmatic or discourse markers, I briefly address this issue here.

As I noted above, Carter and McCarthy categorize TSs as discourse markers (DM), which "link segments of discourse to one another in ways that reflect [speaker's] choices of monitoring, organization, and management" (p. 208); Aijmer claims that a TS has "the form and function of a pragmatic marker" (p. 43) and thus "situates the utterance in relation to other utterances in the discourse" (p. 43). Like many researchers who study discourse and pragmatic markers, Carter and McCarthy and Aijmer seem to be using two different terms for the same function - connecting discourse elements with

\footnotetext{
${ }^{11}$ Schmid claims, correctly, I believe, that the double-is form derives from the canonical single $i s$ form. But his explanation of the double-is phenomenon is unconvincing: speakers emphasize and elongate the copula, then forget that they've produced a copula, and then produce a copula to fill the grammatical need induced by their amnesia (p. 338). He provides no evidence to support this conjecture.
} 
each other. The most developed work in this area is Bruce Fraser's and he defines discourse markers as follows:

For a sequence of discourse segments S1 - S2, each of which encodes a complete message, a lexical expression LE functions as a discourse marker if, when it occurs in S2-initial position (S1 - LE + S2), LE signals that a semantic relationship holds between S2 and S1 which is one of: a) Elaboration; b) Contrast; c) Inference; or d) Temporality. (Fraser 2005: 5)

Fraser (p. 13) also claims that DMs are not necessary for the correct interpretation of the discourse segments they connect; that "is due to the linguistic interpretation of the segments, taken together with the discourse context, and the DM merely makes clear what relationship the speaker intends."

Essentially, DMs function as two place predicates signaling the semantic relation between the segment they introduce and another segment. While Schmid argues that certain shell nouns work in this way, I believe that TSs warrant a different analysis, primarily but not exclusively, because of the semantic schematicity of thing. TSs indicate that the discourse relationship between their complements and the context immediately prior to them is not what it would be if the TS clause were unmarked (see section 6.1 below). They separate rather than connect discourse segments, though Aijmer's characterization of them as "situating" one utterance relative to another is vague enough to accommodate this - and far more besides. And her remark that TSs have "primarily textual function" is far too underdeveloped to test here as we do not know how textual functions differ from the topical, epistemic, and rhetorical functions she describes. (See Delahunty 2011a for a more detailed discussion and Blakemore 2004 for a critique of the discourse marker approach.)

\subsection{Summary of section 4}

Miller and Weinert, Carter and McCarthy, Tuggy, and Schmid all describe the function of the TS as focusing attention on the complement clause. Carter and McCarthy, Aijmer, and Schmid claim that TSs are discourse or pragmatic markers and thus link their clauses with context. Biber et al. and Aijmer say that TSs affect the trajectory of the discourse topic. Carter and McCarthy, Tuggy, and Schmid add that TSs signal that the clause represents a problem, which I assume can be interpreted to include Aijmer's notion that when combined with but, TSs can express opposition or rejection. Schmid claims that TSs present the propositions represented by their clauses as facts. Aijmer claims that TSs have "conventionalized the rhetorical meaning of explanation or justification for a point of view expressed in the prior context" (p. 43), to which Schmid adds reason and cause. Additionally Aijmer claims that TSs may add a new argument, but that they have "primarily textual function" (p. 44), by which she apparently means that they function as pragmatic markers. However, she does not say what this function is nor how it is related to the other functions she claims for TSs.

Neither Miller and Weinert nor Carter and McCarthy attempt to explain how TSs have the effects they claim for them, though this is appropriate for the latter as it is a comprehensive descriptive grammar. The others offer a variety of explanations. Aijmer claims that the extra meanings arise as ad hoc implicatures which are retained and 
conventionalized if they are useful. Tuggy accounts for the attention-focusing effects of TSs by claiming that thing means "noteworthy thing," which he derives from the semantic schematicity of thing, though he does not articulate how. Schmid's remarks about the propositional redundancy of the TS matrix - derived from Tuggy's work suggest a basis for an explanation, but he does not develop this suggestion into an explicit account. Nor does he explain how TSs communicate that the propositions represented by their complements are factual and function as reasons or causes for other elements of the discourse world.

I show below that we can characterize the discourse functions of TSs considerably more precisely and richly than that they just focus attention on their complements; that they signal something more general than a problem or an explanation/justification/cause/ground for an opinion expressed in the preceding context, and I reject the claim that these meanings are conventionalized ad hoc implicatures and that a TS is just another pragmatic or discourse marker. I show how all these effects can be derived from the lexis, syntax, and semantics of the form interacting with its context in accordance with general interpretive principles.

\section{Discourse-relevant linguistic characteristics of TSs}

In this section I discuss the linguistic characteristics of TSs that underlie their discourse properties.

\subsection{TSs are specificational sentences}

Specificational constructions typically consist of a subject representing a variable, a copula which adds nothing to the truth conditions of the sentence, and a complement representing a value of the subject variable.

The categorization of the subtypes of copular sentences is currently an area of intense research and there is considerable disagreement about how many subtypes to recognize and about the criteria for distinguishing amongst them. Consequently I will take a conservative position and assume that there are three distinguishable types - the predicational (or ascriptive per Huddleston and Pullum 2002), the equative, and the specificational (Mikkelsen 2005). Predicationals predicate a property of a referential subject; equatives indicate that the referent of the subject is the same as the referent of the predicate complement; and specificationals assign the property denoted by the subject to the referent of the predicate complement. ${ }^{12}$

Schmid (2000) and Delahunty and Velazquez-Castillo (2002: 50) describe TSs and paradigmatically related sentences with other subject head nouns as "characterizing" the referent of the predicate complement. Francis (1994) claims that the nouns that can head the subjects of these sentences "discourse label" their predicate complements. These works are agreed that the subject of these constructions characterizes the way in which the referent of the predicate complement is to be interpreted in its context. These ways

\footnotetext{
${ }^{12}$ I take no position on Mikkelsen's proposal that specificationals are inverted predicationals, but see Beyssade and Dobrovie-Sorin (2008).
} 
of talking about TSs and their paradigmatic relatives are consistent with their analysis as specificational copular sentences.

Higgins (1976), which brought this semantic type to the attention of modern linguistics, identifies a number of grammatical characteristics of specificational sentences, though only some of these are applicable to the Thing sentences studied in this paper. The most prominent of the applicable characteristics is that their subjects and complements may be reversed:

a. The thing is that it can be done.

b. That it can be done is the thing.

Clearly both of these are grammatical, although they would occur in different contexts.

Another characteristic of specificational sentences is the typical definiteness of the subject NP, a feature that is important to my explanation of how Thing sentences interact with the discourse in which they are embedded, and which was noted by Delahunty and Velazquez-Castillo (2002) and Brenier and Michaelis (2005).

\subsection{Thing}

Thing is, perhaps, the least semantically specified noun in English. It simply denotes the class of countable entities; cf. stuff. We must distinguish two important uses to which it can be put.

(20) a. What has the cat broken now? The thing is a dreadful nuisance.

b. What is a dreadful nuisance? The cat.

(21) a. Someone once suggested that if I intend to leave the site unupdated for a long period of time I should at least leave a little note so that everyone doesn't keep checking back everyday hoping to see a new episode. The thing is, I've never intended to abandon the website; it just happens that way. This time, however, I'm looking at my calendar and I think that I can say that there will not be a new episode in December.

(http://www.bohemiandrive.com/log.rss2)

b. *What is that I've never intended to abandon the website? ??The thing.

Thing in (20a) is a general noun (Halliday and Hasan 1976: 274-6), and the phrase The thing is anaphoric, as it refers to the cat mentioned in the utterance just prior to it, and as such it can be questioned, as (20b) shows.

The thing in (21a) functions differently. As it has no antecedent in its co-text, it is neither anaphoric nor cataphoric, and as (21b) shows, it cannot be questioned. So it appears to be non-referential, or at least not referential in the way the thing in (20a) is. This is the use of the thing with which we are engaged in this paper.

In this respect, thing is similar to other words, such as it, there, and that which on some occasions of use are referential in the normal sense, but under other circumstances are, or seem to be, non-referential but are interpreted as either syntactic markers or as having discourse effects. 


\subsection{Definiteness, referentiality, and singularity}

The vast majority of TSs and their paradigmatically related forms with shell nouns have singular definite subjects. ${ }^{13}$ Delahunty and Velazquez-Castillo (2002: 53) found that $97 \%$ of their examples were definite, and Brenier and Michaelis (2005) found that so many of their examples were definite that they concluded that definiteness is a defining characteristic of the construction. Definiteness indicates existence, accessibility, and exhaustiveness (Lyons 1999), and as the subject is count and singular, its singularity and definiteness indicate that there is only one thing relevant at the point in the discourse where the TS occurs, viz., its complement clause.

Massam (1999) claims that the subjects of TSs and related constructions are non-referential; Brenier and Michaelis (2005) claim that such subjects display features that "favor a nonreferential analysis" (p. 55), including that they "are highly lexically restricted, they have an invariant morphological form (they contain the definite article), and they do not appear to refer to generic, discourse-old, or hearer-old referents" (p. 55). However, Brenier and Michaelis also point out features that favor a referential analysis: the subjects allow contrastive modifiers and they can serve as textual antecedents, though by definition this does not apply to the TSs that are the focus of this paper.

We can resolve the contradiction between Massam and Brenier and Michaelis by assuming that TS subjects do refer but that they refer to metalinguistic entities rather than to ordinary referents. This is consistent with earlier analyses, such as Francis (1994), in which words such as thing and problem are said to "discourse label" relations among propositions or discourse segments.

This is also consistent with the analysis of related sentence types in Huddleston and Pullum (2002: 402-3) and Schmid (2000): the subject represents a description which the complement fits and which may be used by interpreters to determine the relationship between the proposition denoted by the clause and its context.

The subject's definiteness also marks it as given or accessible or identifiable by the interpreter (Lyons 1999; Lambrecht 1994; Chafe 1976). However, as there is no situational referent to be identified, the identifiability characteristic of definite NPs is interpreted in the case of TSs as the speaker's assumption that the hearer accepts the description represented by the subject and that there is some contextually relevant entity that satisfies that description, namely, the proposition represented by the complement clause.

\subsection{The TS matrix does not contribute to the truth conditions of the form}

It is a straightforward matter to demonstrate that TSs and their unmarked counterparts have the same truth condition - each implies the other. Thus if it is true that The thing is that it can be done, then it is true that It can be done. Conversely, if it is true that It can be done, then it is true that The thing is that it can be done. Additionally, The thing is it can be done and it can't be done is contradictory, as is It can't be done and the thing is it can be done. Because the matrix does not contribute to the truth conditions of the

${ }^{13}$ COCA searches for things are and things were returned no TSs See Delahunty (2011a) for more details. 
construction, the primary informational content of a TS is the proposition represented by its clause.

\subsection{The complement clause}

Because the complement of a TS is a complete finite clause, it can be pragmatically developed into a full proposition, e.g., along the lines laid down in relevance theory for the development of explicatures (Sperber and Wilson 1995: 177-193). It represents the unmarked form of Thing sentences and the truth conditions of the sentence as a whole.

\subsubsection{The complement proposition is presupposed}

Because the subject is definite and the construction is specificational, the proposition represented by the clause is presented as presupposed and therefore to be accepted as part of the background assumed by speaker and addressee. That TSs presuppose the truth of their complements is demonstrated by the fact that they pass the standard test for presupposition, viz., their truth is preserved under negation: It works may be assumed to be true in both The thing is that it works and The thing is not that it works. In support of this latter claim, consider the following:

(22) The thing is not that it works - it does, but that's not the issue - the thing is that it works too slowly. ${ }^{14}$

The TS highlighted in the following fragment provides authentic support for my claim:

(23) "Didn't it seem unusual to you, sir: that amount of money in the one account?"

"We did write to Mr. Mackie from time to time, asking if he'd like to discuss other options. Thing is, you can't be too pushy."

"Or the customer might take umbrage?"

Mr. Robinson nodded. "This is a wealthy place, you know. Mr. Mackie wasn't the only one with that kind of cash at his disposal." (Rankin 2000: 95)

The proposition represented by "You can't be too pushy," which is new to the discourse at this point, is clearly taken for granted by Rebus as it functions as the background for his question, "Or the customer. . .?" Robinson's nod confirms this interpretation.

\subsubsection{The complement proposition is unique and exhaustive}

The singularity of the TS subject implicates that there is only one proposition to be taken into account at the point in the discourse at which it occurs and that the proposition represented by its complement is that one. The uniqueness of the

\footnotetext{
${ }^{14}$ TSs with matrix negation are quite rare. A WebCorp search for thing is not returned only one in a hundred, and it was the first of a tandem pair of negative and then positive TSs.
} 
complement is demonstrated by the unacceptability (and perhaps ungrammaticality) of the following conjoined TSs:

??The thing is that it's not my phone and the thing is that it can't be transferred.

Though they might initially appear to contradict my exhaustiveness claim, the two TSs in the following fragment actually demonstrate it:

(25) [B.18] So, you got to make, uh, so how do you keep track of where you are in, in your monthly spending?

[A.19] Well, the thing is, is that, um, I ba, I basically know how much I have, right?

[B.20] Right.

[A.21] And so, the thing is, is that I, I can tell like, uh, I, I get all my money out of the teller.

[B.22] Yeah.

(SW 2092)

The TS in [A.19] begins A's answer to B's question about how A keeps track of his monthly spending. In addition, "how much" in [A.19] is dependent for its full interpretation on "monthly spending" in [B.18]: it is elliptical for "how much money," or something similar. So this TS implicates that the proposition, I basically know how much money I have, is all B need attend to at this point. This is supported by A's comprehension and agreement check, "Right?" to which B responds with his agreement "Right." These two together close out this discourse or topic segment, thus allowing A to move on to his next topical item.

A begins his next utterance with "And so" but seems to do a restart formulated as a TS. An utterance beginning with "And so" would be interpreted as a conclusion following from a prior utterance. This does not seem to be what he wants to communicate. Rather, he seems to want to communicate the reason why he knows how much he has at any time, viz., he can tell because he gets all his money out of the [automatic] teller [machine], which presumably provides him with a receipt with his balances printed on it. B's "Yeah" indicates his understanding and acceptance of [A.21] and closes that topical segment. ${ }^{15}$

\subsubsection{The complement proposition is focused}

In addition to being presupposed, the TS complement clause is also focused. Lambrecht (1994: 223) distinguishes between predicate focus, sentential focus, and argument focus. Absent any indication to the contrary, the predicate of a sentence is its unmarked focus, and so, because the clause is in the predicate, it is focused.

15 The Thing sentence in [A.19] also indicates that A's and B's contextual assumptions are somewhat incompatible. B's question assumes that A has some way of keeping track of his expenses. But the "well" that prefaces [A.19] indicates that A does not keep track of his expenses in the way that he assumes B has in mind. He "basically know[s] how much [he] has" to which [A.21] adds that he "can tell" because he gets all his "money out of the teller." 
Argument focus is what the name implies - focused by virtue of being an argument of a predicate. Lambrecht claims that argument focus is marked (p. 296). Because they are specificational structures, TSs fit Lambrecht's argument focus pattern. That is, the subject is a predicate and the complement clause is its argument and therefore a marked focus. The TS complement clause is thus doubly focused.

\subsection{Summary of section 5}

TSs are specificational sentences with singular, non-referential, definite subjects. Because the subject is definite it licenses the presupposition that an identifiable denotatum exists, viz., the proposition represented by the clause, which is uniquely and exhaustively relevant in the context. And because the clause is both predicate and argument of the subject it is doubly focused.

\section{What do TSs communicate?}

What TSs communicate is a function of their linguistic characteristics. Here I discuss a range of interpretations of TSs, including ones proposed in the research literature reviewed above. I begin with a demonstration that TSs and their unmarked counterparts function differently in context.

\subsection{Thing sentences and their unmarked counterparts function differently in context}

When we contrast TSs occurring in original fragments of text with their unmarked counterparts in the same context, and vice versa, we intuit a clear difference between the originals and the altered versions.

(26) The man brought a notepad out of his pocket, scribbled something on it while still holding his cane, tore the sheet off and handed it to the second man, who read it and nodded.

...

"Who was that?" Rebus asked.

"That was Major Weir."

$\cdots$

"What was the note all about?" Rebus asked.

"The Major doesn't say much. He communicates better on paper." Rebus laughed . .

. "I'm serious," Minchell said. "I don't think I've heard him say more than a couple of dozen words all the time I've worked with him."

"Something wrong with his voice?"

"No, he sounds fine, a little croaky, but that's to be expected. Thing is, his accent is American." (Cf. His accent is American.)

"So?"

"So, he wishes it was Scottish."

(Rankin 1997: 137-8)

The TS here contributes to the coherence of the text in ways that its unmarked congener does not. In fact, when the unmarked form replaces the TS, the text becomes 
incomprehensible. Clearly, TSs and their unmarked forms function differently in context and, if Fraser (2005) is correct in claiming that DMs merely signal an already existing relationship, then clearly TSs are not DMs.

The underlying logic of fragment (26) is that Weir communicates by writing notes rather than by speaking because his accent is American, which he wishes to conceal because he wishes it were Scottish. This logic emerges over a series of conversational turns rather than being directly and most simply expressed.

At the point at which he asks, "Something wrong with his voice?" Rebus expects Minchell either to endorse his conjecture that Weir communicates by writing rather than by speaking because there is something wrong with his voice, or, if that is not the explanation, then to say so and provide the actual explanation. Minchell does reject Rebus' speculation and elaborates on why it is incorrect (Weir sounds fine, if a little croaky), and continues with the TS.

The TS replaces Rebus' speculation that Weir doesn't speak because there is something wrong with his voice, and supplies the actual reason - Weir's accent is American. Rebus finds this incomplete as a reason for Weir's not speaking and asks for more information, which Minchell then provides.

If Minchell had used the unmarked counterpart of the TS, Rebus would have understood it either as simply an additional piece of information about Weir, or as an explanation for why Weir's voice was croaky (to see this potential interpretation clearly, replace croaky with foreign). On the first reading, Rebus' "So?" would be interpreted as "So what?" that is, as questioning the relevance of the unmarked form. On the second reading, Minchell's two sentences would make no sense - having an American accent does not make one's voice croaky - and therefore Rebus' "So?" would make no sense either (imagine if Rebus said "Huh?" instead of "So?"). Neither of these interpretations is integratable into a coherent interpretation of Minchell's whole utterance in its context.

So, the TS prevents its complement from being interpreted as if it were simply juxtaposed to its prior. (It also prevents the interpretation the complement clause would have if it were conjoined to its prior context by and: compare the effects of replacing the original TS with and his accent is American. See Carston 2002, esp. ch. 3, for discussion of how the interpretations of juxtaposed and conjoined utterances differ. See also Bar-Lev and Palacas 1980; Blakemore 1987.) Thus the TS effects a partial topical disjunction between its prior and its complement. This disjunction is partial because it does not effect a complete change of topic, just a shift to another aspect of the same topic, in this instance, from Minchell's rejection of Rebus' speculative explanation for Weir's preference for writing rather than speaking to the actual explanation for this.

However, coming after the TS, Rebus' "So?" functions as an indication that the TS does not provide him with an adequate explanation for Weir's peculiarity and therefore as a request for more information which he can interpret as the additional premise(s) he needs to explain Weir's behavior. This informational insufficiency is a frequent characteristic of TSs and is the basis for inferences such as that in (14) and for the kind of topical development in (26) and in (28) below.

From this example we can hypothesize that a TS imposes a separation between its immediately prior context and its clause, thereby preventing the interpretation that would be most relevant if the TS clause were unmarked. As a result, TSs effect a change in the expected trajectory of the current topic, though not a shift to a separate topic. In effecting this sub-topical shift, TSs typically also set up the expectation of further discourse. 
Looking at the TS in (26) from the point of view of the list of functions we derived from the prior research, we can see that it fulfills all those functions. The TS clearly calls attention to its clause; we know this because Rebus' "So?" clearly orients to it. It represents its clause as a fact; we know this also because Rebus' "So?" indicates his acceptance of its truth and asks for its relevance. Additionally, adding "though this isn't true" or "though I don't know this" creates a contradiction.

The TS in (26) also expresses a reason for Weir's communicative fetish; we know this because we can paraphrase the relevant part of the interaction as "Weir communicates by writing notes rather than by speaking because his accent is American And effects a subtopical shift from how Weir sounds to why he writes rather than speaks.

This TS may express a problem, or something "in disconformity with something with something usual/established/backgrounded," at least from Weir's point of view, though Rebus' "So?" suggests that he also thinks that it is in disconformity with the usual reasons for writing rather than speaking. However, this interpretation is not imposed by the TS; rather, it is due to the fact that the TS proposition replaces Rebus' question, "Something wrong with his voice?" as the explanation for Weir's oddity .

To be methodologically sound, we should also compare an original non-TS with its replacement in context by its corresponding TS. Compare the highlighted original nonTS with its TS counterpart in the following fragment:

\footnotetext{
"Dickie Diamond was an arsehole, whole world knew it"

"Any of his old cronies still around?"

"There's one of them in here right now."

(Cf. "Thing is, there's one of them in here right now.")
}

Rebus looked around at the disconsolate, blank-eyed faces. "Who?"

Hogan just winked, and waited till the drinks had been paid for. When the barman slouched back with Rebus's change, Hogan greeted him by name.

"Okay, Malky?"

The young man frowned. "Do I know you?"

Hogan shrugged. "Thing is, I know you." He paused. "Still on the smack?"

(Rankin 2004: 192)

Again the coherence of the adapted text is seriously disrupted as a reader processing it is forced to try to create an interpretation in which the TS matrix is essential. The TS implies that the proposition "There's one of them here right now" is to be processed in ways that differ from those in which one would process the non-TS version. One is hard pressed to determine just what those different ways might be, as the original seems to be optimally relevant in the context: it provides a fully adequate answer to Rebus's question, "Any of his old cronies still around?"

We could say with Miller and Weinert and Carter and McCarthy that TSs "highlight" or "direct attention to" their complement clauses in ways that their unmarked counterparts do not, though clearly we need to be considerably more precise than that. 


\subsection{TSs may represent both problems and solutions}

As several of the authors represented in the prior research have claimed, TSs may be interpreted as a problematic state of affairs. This is particularly obvious in (14), repeated here:

(14) A. Can I have this transferred to my phone upstairs?

B. Well, the thing is that it's not my phone you're calling from

A: OK.

(London-Lund Corpus; mark-ups removed)

where B's response is to be interpreted as an account for why A cannot have his call transferred, surely a problem from B's point of view.

Solutions are the logical and/or rhetorical complement of problems, and although Schmid does not include TSs among his class of SOLUTION expressions, the TS in the following fragment must clearly be interpreted as representing a solution rather than a problem.

(28) Mackenzie was shaking her head. "These records are up-to-date. The last rent money we received was only last week. It was paid by Mr. Baird."

"You're thinking he sublet?"

A broad smile lightened Mrs. Mackenzie's face. "Which is strictly forbidden by the tenancy agreement," she said.

"But people do it?"

"Of course they do. The thing is, I decided to do some sleuthing myself. . ." She sounded pleased with herself. Rebus leaned forward in his chair, warming to her.

"Do tell," he said.

"I checked with the city's other housing areas. There are several Robert Bairds on the list. Plus other forenames, all with the surname Baird."

(Rankin 2005: 84)

Once Mackenzie has uttered her TS, her sleuthing is taken for granted by Rebus (and readers) and it re-directs Rebus' attention from illegal subletting in general back to Baird's illegal renting activities. The information that Mackenzie had done some sleuthing would not on its own have been informationally sufficient in its context. However, as evidence for, "She sounded pleased with herself," it leads us to expect that her sleuthing has paid off, which is the assumption underlying Rebus' leaning forward and saying "Do tell," which is rewarded with the information she provides in her next utterance. Clearly, because Mackenzie's sleuthing represents a solution rather than a problem, Carter and McCarthy's and Schmid's claims are far too narrow and we need an analysis that better describes the discourse functions of TSs.

\subsection{TSs may represent explanations, justifications, reasons, or causes for states of affairs}

Several of the authors cited in the prior research claimed that TSs may be interpreted as explanations, justifications, reasons, or causes of some state of affairs, meanings which Aijmer claims have become conventionally associated with The thing is that. Though 
only a few of the TSs in my data can plausibly be so interpreted, nonetheless, this interpretation is clearly illustrated by the TS in (14), which can be interpreted as an explanation, justification, reason, or cause for why A cannot have his call transferred to the phone upstairs; his "OK" indicates that he understands and accepts this interpretation.

Likewise, Minchell's TS in (26) expresses a reason for Weir's communicative fetish; we know this because we can paraphrase the relevant part of the interaction as 'Weir communicates by writing notes rather than by speaking because his accent is American and he wishes it were Scottish.'

Aijmer claims that a TS may also add an argument. However, if we interpret her claim as simply expressing a reason for something - which is, after all, what arguments express - then we can subsume her characterization under the more general function of expressing reason, cause, justification, and the like.

Reasons, explanations justifications, and causes are specific articulations of the more general relation of logical antecedent or premise from which conclusions - the situations for which reasons, explanations, justifications, or causes are presented - may be derived (see Delahunty 2001 and references therein for further discussion). As we've seen, B's response in (14) may be viewed as a premise from which A can derive the conclusion that B cannot transfer his call.

\subsection{TSs may represent conclusions}

None of the authors cited in the prior research claims that a TS may represent a conclusion (the logical complement of premise) to be drawn from its context, though this is how the italicized TS in (29) must be interpreted.

(29) Anyway. Status update. They've found me a room. I've unpacked my adaptor plug. My PowerBook is charging itself up. I'm still not using it, though because I am now lying in the bath. So I'm still using the Psion. I have never written anything in the bath before. Paper gets damp and steamy, pens won't write upside down, typewriters hurt your tummy, and if you are prepared to use a PowerBook then I assume that it isn't you own PowerBook.

So the thing is, it can be done. You can actually write on a palmtop computer, which is something I didn't realize before. I had tried to do it on Sharp Wizard, but it wasn't possible because the keyboard was laid out alphabetically which is hopeless.

(DNA/The Little Computer that Could. http://www.douglasadams.com/dna/980707-02-a.html)

So in this example is an explicit discourse marker of conclusion, though even without so, the TS would be interpreted as a conclusion to be drawn from the information in the prior paragraph, as Fraser (2005) claim is generally true for DMs. If TSs were conventionally interpreted as causes or reasons, then prefacing them with an explicit marker of conclusion would render them contradictory, which, of course, this example is not. Additionally, as a conclusion, this TS is, in this respect, in conformity, not in disconformity with its prior. 


\subsection{TS complements may be interpreted other than as premises or conclusions}

Many of my TSs cannot be interpreted either as premises (or as any their more specific interpretations) or conclusions. The TS below is typical:

(30) The current version [of Yahoo Go] can open picture attachments; the final version, Yahoo says, will also let you open Microsoft Office documents, among other enhancements. It is coming in late June. The thing is, Yahoo Go offers eight Internet functions - not just email, but also Flikr photos, Web search, maps, weather and various news categories. Unfortunately, because Yahoo Go is so much more ambitious than Gmail for Mobile, it's much slower, and runs on even fewer phones.

(http://www10.nytimes.com/2007/05/24/technology/24pogue.html?)

Yahoo Go offers eight Internet functions - not just email, but also Flikr photos, Web search, maps, weather and various news categories does not function as a premise from which either its prior or following propositions follow as a conclusion; nor does it function as a conclusion following from either its prior or following propositions. Rather, this TS marks a topical transition from the contrast between the current and new versions of Yahoo Go and when the latter is to be released, to the limitations of Yahoo Go that are due to its ambitious range of applications.

\subsection{Summary of section 6}

TSs and their unmarked counterparts support different discourse functions. The function of TSs appears to be to effect a subtopical shift in the local discourse. TSs are interpretable as problems and solutions, and as premises and conclusions (and their more specific interpretations as causes, reasons, justifications and effects, results, and consequences). However, these interpretations are independent of the TS form.

\section{Other discourse effects of TSs}

In this section I discuss several TS effects that emerge when we look at them in context from alternative theoretical perspectives, specifically politeness theory (Brown and Levinson 1978) and conversation analysis (Lerner 2004).

\subsection{Politeness effects}

Politeness theory (Brown and Levinson 1978) claims that redressive action frequently requires elaboration of the message. As the proposition represented by a TS clause is the sentence's message, we can view the semantically minimal matrix as elaboration, which may indicate increased politeness. Politeness theory also claims that "[o]ne way of indicating that $\mathrm{S}$ doesn't want to impinge on $\mathrm{H}$ is to phrase the [face threatening act] as if the agent were other than $S^{\prime \prime}$ (p. 195) thus impersonalizing a message. Because TSs 
represent their propositions as presupposed and therefore not asserted by the speaker, they are politely impersonal. ${ }^{16}$ All of these features can be seen in example (14) above.

\subsection{TSs project further discourse}

TSs set up expectations for the discourse that follows them. They often accomplish this by being relatively uninformative in the context, as indicated by Rebus' "So?" in example (26). The italicized TS in example (29) functions in this way, too, and demonstrates that TSs may be exploited in written English to introduce paragraphs and function as their topic sentences. The TS is exploited in that example to mark a change in subtopic, from a discussion about writing with various instruments in the bath back to the earlier topic of using the Psion.

The TS in (31), from a web site to which one can write for advice about cars, illustrates the same phenomenon. The assumption on which the query is based is that new cars can normally be expected to start.

(31) just got this new 2003 voyager. the thing is that, the other day it didn't start in the morning. (would not turn the engine). I try it again and would you believe it? No lights come on on the dashboard, wont turn the engine nothing is happening. Change the battery, check the fuses, etc etc. What is it with it? Could you help please????????? Ta very much. (http://www.faqs.org/qa/qa-3417.html)

The TS marks the topical shift from the fact that the writer had just got a new Voyager to the fact that it wouldn't start. The TS clause, the other day it didn't start in the morning, provides very little information, and thereby makes relevant further information, in this case, a description of the symptoms exhibited by the car, which exemplify the car's failure to start, a list of some of the things the owner did to remedy the problem, and a request for help with the situation.

\section{3. “Pre-” effects}

Mackenzie's TS in (28) functions as a bid for an extended next turn. Her TS anticipates, "projects," to use Hopper and Thompson's (2008: 105-6) term, further talk by its producer and Rebus' "Do tell" indicates that he recognizes and accepts her bid, and cedes interactional space for her additional talk. If we look at this TS from a conversation analysis point of view, it functions as a "pre-" (Levinson 1983: 356), specifically as a pre-story - cf. pre-requests, pre-announcements (Terasaki [1976] 2004), which prefigure aspects of their producers' intended next utterance and provide a basis upon which recipients can decide to accept or reject the bid.

\footnotetext{
${ }^{16}$ Pusch (2003) calls attention to the politeness effects achieved by the indirectness with which inferential/sentential focus cleft sentences present their messages. Günthner (2012), which I discovered too late to fully integrate into this paper, claims that the German equivalents of Thing sentences introduce face threatening acts.
} 


\subsection{Discourse "disconformity"}

Tuggy and Schmid claim that TSs mark their propositions as being in "disconformity" with elements of their contexts. Schmid relates this to their sometimes indicating a problem relative to their contexts, though he claims that TSs may be also be neutral in this regard. In this section I show that TSs may indicate a subtopical discontinuity.

The italicized TS below in (32) occurs in a report of an interview in Penn Current. Q's initial question sets the general topic, the changes in astronomy over the past few decades, but he explicitly focuses this general topic with his second question on the impact of technology on the field.

Q. How has the field [astronomy] changed over the past few decades? I imagine technology may have made a big impact?

A. Indeed, technology has really helped us a lot. The thing is, the tools are becoming more and more expensive, so [projects] (sic) need to involve many, many more people. Astronomy, up until now, has been a field where you can have a group of 15 or 20 people get together and do something that will have a big impact.

(http://www.upenn.edu/pennnews/current/2006/041306/cover.html)

A begins his answer by agreeing with Q's assumption that technology has made a big impact in the field and then uses a TS to indicate a shift of subtopic away from that proposed by the interviewer to his concern about the cost of that technology.

Because they indicate a partial disjunction with their prior contexts and their clauses are presupposed, TSs may be interpreted as contradicting and substituting for a presupposition expressed in the immediately prior context.

(33) I imagine that the hour you are onstage each week is high-energy and exhausting. Do you have fun doing the show each week? What's the funniest unexpected thing that's happened onstage during the run?

... The thing is that since the plays are done in random order and, since there is a lot of audience participation, the whole thing is rather unexpected.

(Interview re. Too much Light Makes the Baby Go Blind.

http://www.nytheatre.com/nytheatre/voiceweb/v_flynn.htm)

In this example, the interviewer's definite article and superlative "funniest" license the presupposition that there exists a (unique) "funniest unexpected thing that happened onstage during the run." This presupposition is presented as to be taken for granted, but is implicitly contradicted and replaced by the proposition represented by the TS in the interviewee's reply.

Using the TS here has the effect of indicating that interviewer and interviewee are operating under different assumptions. Or at least that the interviewee acts as if this were the case. Specifically, that the interviewer does not know, or has not taken into consideration, the fact that the plays are done in random order, and that this has to be taken into consideration in answering the question about the "funniest unexpected thing that's happened onstage during the run." This may be interpreted as a specific manifestation of the disconformity associated with TSs according to Tuggy.

It is important to note that this interpretation of the TS is due, not to any conventionalized meaning associated with the TS, but to the interpreter's search for a 
contextually appropriate interpretation of the TS. An interpreter searching for such an interpretation of the TS in (33) might reason thus: This TS occurs immediately after a question, a position which can be filled in a number of ways. It might be filled with something entirely irrelevant to the question, though this is clearly not the case here, as the TS continues the topic of the question and includes a repetition of "unexpected." Alternatively, the position could be filled with a response projected by the question substitution for a $w h$-phrase in this instance. However, this TS cannot be interpreted simply as a replacement for the interviewer's "What."

However, the post-question position may also be filled by a response that addresses some issue raised by the question, such as its contextual appropriateness or its assumptions. As the TS marks its clause as focused and presupposed and as its content is about the "unexpected" onstage, it would therefore be most straightforwardly interpreted as addressing what its speaker sees as an invalid assumption on the part of the interviewer, in conversation analysis terms, other-initiated, other-repair.

While the contradicted assumption is relatively explicit in (33), it may also be quite implicit as in (14), where B's response - The thing is it's not my phone you're calling from - indicates that $\mathrm{B}$ assumes that $\mathrm{A}$ assumes that $\mathrm{B}$ owns the phone $\mathrm{A}$ is currently using, but the TS clause represents a premise from which A is to conclude that $\mathrm{B}$ cannot transfer his call to the other phone.

The TS in fragment (29) - So the thing is, it can be done - is introduced by so, which indicates that the proposition it introduces is to be interpreted as a conclusion derivable from the local context. If a TS can be so interpreted, then presumably it is in semantic or logical conformity. However, the TSs in (14), (29), (32) and (33) all indicate a shift to a new trajectory of the topic at hand, and so might be viewed as marking a topical disconformity. However, my data strongly suggest that any disconformity associated with TSs is reducible to subtopical shifts triggered by the presentation of the clause as focused but presupposed.

\subsection{Dispreferredness effects}

Conversation analysts differentiate preferred from dispreferred second turns. The latter are characterized by delays, prefaces, accounts, and indirect or mitigated declinations (Levinson 1983: 334). With this in mind, consider the TS (B2 and B3) in the following text from the London-Lund Corpus, on which (14) is based:

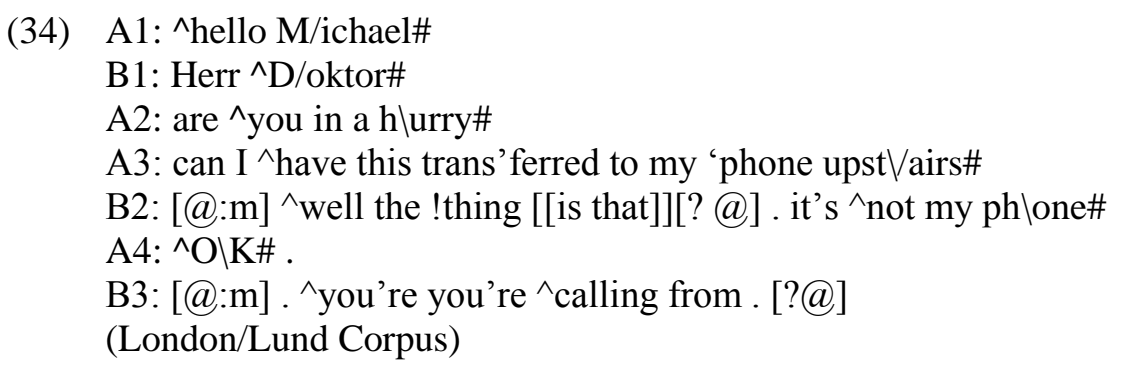

B’s “[@:m]” constitutes a delay, his “^well” is a preface indicating an upcoming dispreferred response, his TS matrix also delays the presentation of his "it's ^not my phlone\#," which A takes as a premise from which to conclude that B cannot have the call transferred and thus as an indirect declination, as his "^ $\mathrm{OKK \# ."} \mathrm{indicates.}$ 


\subsection{Summary of section 7}

The TS matrix indicates that the TS clause has a different relationship to its prior context than its unmarked version. In this respect it is like the matrixes of inferentials, it-clefts, wh-clefts, and not that sentences. TSs differ from these by virtue of the difference in matrix subject head noun. Shell nouns other than thing specify the relationship between their complement clauses and their contexts. The semantic underspecification of thing provides no such information and so does not constrain the relationships in this way.

While the interpretations of TSs include both premises (justification, cause, ground, reason) and conclusions, as well as other discourse relations - which derive from the normal operation of the interpreter's search for the relevance of utterances - their main function seems to be to introduce into the discourse a proposition that is simultaneously new, focused, and presupposed, and thereby to effect a discontinuity or unexpected turn in the trajectory of the current topic. As a result TSs relate to their prior and following co-text differently than their unmarked counterparts would. This claim implies the further claim that TSs cannot occur in discourse or topic initial position, and this is consistent with the fact that none of my examples occur in those positions, though a more focused data search is warranted.

Additionally, the elaboration introduced by the TS matrix allows the con- struction to also function as a marker of politeness and of dispreference.

We have now established the functions TSs play in discourse, and must turn to an explanation of these behaviors.

\section{How TSs do what they do in context}

In this section I lay out how I believe TSs function in discourse as they do.

TSs are specificational constructions, so their subjects are characteristically definite and represent a variable whose value is represented by their complements (Higgins 1976; Huddleston and Pullum 2002: 266 ff.)

The subject represents a description which the complement fits and which may be used by interpreters to determine the relationship between the proposition denoted by the clause and its context.

Because the description provided by thing has such minimal semantics, it provides no specific directions to its interpreter on how to interpret it in context. In this respect it differs from analogous sentence types with semantically richer subject heads, such as problem, trouble, or reason which impose a specific relation between the prior context and the complement clause by evoking a "frame" that incorporates the complement clause and a segment of relevant context (Delahunty and VelazquezCastillo 2002: 53-4; Schmid 2000: 88). Because its subject does not specify otherwise, a TS cannot evoke such a frame and so must be interpreted in ways that take into account what information its matrix does offer. ${ }^{17}$

Ordinarily, definite NPs refer to cognitive representations of entities in the discourse world. These representations typically have discourse antecedents, contextual

\footnotetext{
${ }^{17}$ Earlier researchers (Tuggy, Schmid) also invoked the semantic inspecificity of thing as part of their accounts for the interpretations they attributed to TSs, but they stopped short of including the other information included in TS matrixes in their explanations.
} 
referents, or are licensed by bridging assumptions. However, TS subjects have no antecedents or situational referents and are not licensed by bridging. In spite of this lack, the definiteness of the TS subject licenses the presupposition that a denotatum exists, in accordance with something akin to Lewis' (2004 [1979]: 804) rule of accommodation for presupposition:

If at time $t$ something is said that requires presupposition $P$ to be acceptable, and if $P$ is not presupposed just before $t$ then - ceteris paribus and within certain limits presupposition $P$ comes into existence at $t .^{18}$

Because, at the time a TS is produced and interpreted, the definiteness of the TS subject requires the presupposition that a thing exists, the interpreter creates a mental representation of the thing at that point in the discourse. But because the thing has no referent in the discourse world, it is taken to be an almost vacuous description of a variable whose value is specified by the clause.

In addition to being presupposed the complement clause is also focused. And because it is focused, it represents a proposition that is new to the discourse at the point at which the TS occurs. As a marked focus, it will typically be interpreted as contrasting with some other locally relevant proposition, generally that licensed by the immediately prior discourse segment.

Because the TS clause is both presupposed and focused, it is introduced into the discourse as a new member of the set of assumptions to be taken for granted in the context and which is to form the context for the interpretation of the following discourse segment, thus contrasting with and displacing the immediately prior proposition from that role. This accounts for the sense of problematicity or disconformity claimed for TSs by Carter and McCarthy, Tuggy, and Schmid.

As the context for the following discourse, the proposition represented by the TS will be interpreted in whatever way the search for its relevance in its context determines, which may be as a premise as in (14), or as a conclusion as in (29), or otherwise (31). Premises can be further interpreted (or paraphrased by analysts and discourse participants) in their contexts as causes, reasons, justifications, grounds for

\footnotetext{
${ }^{18}$ Prince (1978) and Lambrecht (1994: 65ff) point out that while the proposition represented by the modifying clause of an it-cleft is characteristically "pragmatically presupposed, i.e., assumed by the speaker to be known to the addressee," there are uses of it-clefts where this assumption is suspended. Consider Lambrecht's example (2.21 p. 71), It was George Orwell who said that the best books are those which tell you what you already know, "uttered by a lecturer to his audience at the beginning of the lecture" (p. 70). "In the discourse situation in which this sentence was uttered, it could not be assumed as a fact known to the audience that some person had made the statement expressed in the who-clause." Such uses of it-clefts are referred to as "informative presupposition" (IP) it-clefts. Lambrecht (p. 71) argues that the IP interpretation is a "conventionally established indirect way of communicating the content of that proposition" due to "conventionalized pragmatic accommodation," and is thus outside the purview of Lewis' rule. One might be tempted to argue that the TS clause has the information status of "informative presupposition." However, there is no type of TS that has the kind of "qualitative difference" from some other TS type that Lambrecht (p. 71) claims the IP it-cleft has from the basic itcleft; for example, there is no sense that the TS clause is known to the speaker and a third party but not to the intended audience, so there is no motivation for invoking anything like "conventional pragmatic accommodation" in the interpretation of TSs. Consequently there is no basis for not appealing to Lewis' rule.
} 
conclusions. And conclusions may be further interpreted as effects, results, or consequences.

We can explain how TSs come to be interpreted as premises and conclusions without appealing to the conventionalization of ad hoc implicatures. Carston (2002), in a section she calls "Cognitive Fundamentals: Causality and Explanation" (pp. 235-242), claims that "we are explanation-seeking creatures, so that, in general, when we register a new fact about the world, we look for an explanation for it" (p. 237). She proposes that we adopt a very general interpretation schema: "when we register a new piece of information, $\mathrm{P}$. . . we standardly construct a 'P because ' assumption schema, the completion of which will be relevant to us" (p. 241). The TS in (26) provides a clear instance of this; for convenience, I repeat the relevant sections of (26) here as (26'):

$$
\begin{aligned}
& \text { "The major doesn't say much." } \\
& \text { "Thing is, his accent is American." }
\end{aligned}
$$

That is, the Major doesn't say much (P) because his accent is American. This TS functions just as Aijmer claims - it provides an explanation for an opinion expressed earlier.

As we saw, contrary to Aijmer's claim that TSs follow the discourse element they explain, example (23) shows that we also find discourse fragments in which a TS functions as an explanation for a following contextual element. For convenience, I repeat the relevant parts here as $\left(23^{\prime}\right)$ :

(23') "Thing is, you can't be too pushy."

"Or the customer might take umbrage?"

The logic that underlies and connects these utterances is that you can't be too pushy (P) because the customer might take umbrage (Q). ${ }^{19}$

Carston's discussion of causality and explanation allows for a broad interpretation of these relationships, breath that she bases on Aristotle's "four causes" (2002: 239-40). For example, Blakemore (2001: 109), quoting Carston (1992), says that " "exemplification is a common way of providing evidence for a claim or, equivalently, giving a reason for believing something," a relationship illustrated in (31). In that fragment, the list of things the writer did and the symptoms exhibited by his Voyager are examples that provide evidence in support of his assertion, realized as a TS, that his new car did not start, an interpretation that follows from Carston's general interpretive schema without appeal to conventionalization. (See also Blakemore 1997.)

Because the proposition it introduces is new and doubly focused, a TS triggers a shift in the topic of the discourse. But because definite NPs are interpreted as relevant within their local contexts, and specifically within the current topic, the topical effects of TSs are limited to the current topic. That is, the shift they effect is not to a completely separate topic, but to a closely related subtopic, which may be a return to an earlier subtopic, as in (29). Aijmer (2007) agrees that TSs can affect the development of a topic, but she also claims that they can change topics. None of my TS examples do this and the limitation is explained by the definiteness of their subjects.

${ }^{19}$ Alternatively we might analyze this exchange as realizing Carston's "default procedure": "Given two states of affairs P,Q, the one followed hotly by the other, consider P as having caused Q" (p. 238). 
So a TS will be interpreted in context in accord with general pragmatic principles such as the search for optimal relevance, in a manner that is consistent with the presuppositional and focusing constraints imposed by its discourse relevant linguistic characteristics. ${ }^{20}$

\section{Conclusion}

Thing sentences demonstrate that speakers are attuned to the topical and subtopical expectations of their audiences and that they exploit various ways of marking information to manage topical development, specifically to signal an unexpected development of the current topic, leading to changes in its trajectory. Their properties follow from their lexical and syntactic characteristics: a definite subject headed by semantically vacuous thing, in a specificational sentence with a finite clausal complement.

I have discussed in another paper (Delahunty 2011a) the issue of how fixed and formulaic the TS construction is. My data suggests that it is fixed under some discourse circumstances, especially rapid on-line spoken or written production, but fully compositional under others, notably in edited spoken or written communication, except where that is intended to represent rapid on-line production, as in, for example, fictional dialog.

From a diachronic point of view, my data suggests that TSs have not yet accreted meanings that are not licensed by their lexis and syntax, though I expect that if the form of the matrix continues to reduce and if the reduced forms spread across the formality and genre spectrum, then TSs may develop what Aijmer (2007) characterizes as "ad hoc" but "useful" implicatures, though whether these will ever be truly "ad hoc" remains to be seen.

\section{References}

Aijmer, Karin (2007) The interface between discourse and grammar: The fact is that. In Agnes Celle, and Ruth Huart (eds.), Connectives as discourse landmarks. Amsterdam/Philadelphia: John Benjamins Publishing Company, pp. 31-46.

Bar-Lev, Zev, and A. Palacas (1980) Semantic command over pragmatic priority. Lingua 51: 137-146.

Bergh, Gunnar (2005) Min(d)ing the English language data on the Web: What can Google tell us? ICAME Journal 29: 25-46.

Beyssade, C., and C. Dobrovie-Sorin (2008) Copular sentences, lifetime effect, and identity. http://webs2002.uab.es/clt/activitats/Bare\%20Singulars/BeyssadeDobrovieSorin.pdf_ (accessed 4 June 2011).

${ }^{20}$ In fact the construction is rather overbuilt; that is, its effects are redundantly motivated by several of its linguistic features. In particular, the complement clause is multiply focused - it is embedded in a semantically minimal matrix, it is an argument focus by virtue of the specificational semantics of the TS construction, and is default focused because it is in the predicate of its sentence (Lambrecht 1994). 
Biber, D., S. Johansson, G. Leech, S. Conrad, and E. Finegan (1999) Longman grammar of spoken and written English. Harlow, UK: Pearson Education.

Blakemore, Diane (1987) Semantic constraints on relevance. Oxford, UK: Blackwell.

Blakemore, Diane (1989) Denial and contrast: A relevance theoretic analysis of but. Linguistics and Philosophy 12: 15-38.

Blakemore, Diane (1997) Restatement and exemplification: A relevance theoretic re-assessment of elaboration. Pragmatics and Cognition 5.1: 1-19.

Blakemore, Diane (2001) Discourse and relevance theory. In Deborah Schiffrin, Deborah Tannen, and Heidi E. Hamilton (eds.), The handbook of discourse analysis. Malden, MA: Blackwell, pp. 100-118.

Blakemore, Diane (2004) Discourse markers. In Laurence Horn, and Gregory Ward (eds.), The handbook of pragmatics. Oxford, UK: Blackwell, pp. 221-240.

Brenier, Jason, and Laura A. Michaelis (2005) Optimization via syntactic amalgam: Syntax-prosody mismatch and copula doubling. Corpus Linguistics and Linguistic Theory 1.1: 45-88.

Brown, Penelope, and Stephen C. Levinson (1978) Some universals in language usage: Politeness phenomena. In E.N. Goody (ed.), Questions and politeness. New York: Cambridge University Press.

Calude, Andreea S., and Gerald Delahunty (2011) Inferentials in spoken English. International Journal of Pragmatics 21.3: 307-340.

Carston, Robyn (1992) Conjunction, explanation and relevance. Lingua 90.1/2: 23-48.

Carston, Robyn (2002) Thoughts and utterances: The pragmatics of explicit communication. Malden, MA: Blackwell.

Carter, Ronald, and Michael McCarthy (2006) Cambridge grammar of English. Cambridge, UK: Cambridge University Press.

Chafe, Wallace (1976) Givenness, contrastiveness, definiteness, subjects, topics and point of view. In Charles Li (ed.), Word order and word order change. Austin: University of Texas Press, pp. 25-55.

Delahunty, Gerald (1995) The inferential construction. International Journal of Pragmatics 5.3: 341-364.

Delahunty, Gerald (1997) 'Oh, it's I'm not pretty enough' Expletive structure and relevance. In Anders Ahlqvist, and Věra Čapková (eds.), Dán do oide: Essays in memory of Conn R. Ó Cléirigh. Dublin: Institiúid Teangeolaíochta Éireann, pp. 115-122.

Delahunty, Gerald (2001) Discourse functions of inferential sentences. Linguistics 39.3: 517-545.

Delahunty, Gerald (2006) The pragmatics of Not that sentences: "Not that there is anything wrong with that." International Journal of Pragmatics 16.2/3: 213-245.

Delahunty, Gerald (2008) Thing sentences, markedness, topic, register, and mode. Paper presented at First North American Conference on Pragmatics (I NAWPRA), York University, Toronto.

Delahunty, Gerald (2009) Relevance theory, "loose talk," and speaking/writing relations. Paper presented at $7^{\text {th }}$ Annual Hawaii International Conference on Arts and Humanities, Honolulu, HI.

Delahunty, Gerald (2011a) Contextually determined fixity and flexibility in thing sentence matrixes. In Koenraad Kuiper (ed.), Yearbook of Phraseology 2. Berlin: Mouton de Gruyter, pp. 109-135. 
Delahunty, Gerald (2011b) Loose talk and "loose thought": Relevance theory, style and the indication of context. Presented at International Pragmatics Association Conference, Manchester, UK, July 2011.

Delahunty, Gerald, and Laura Gatzkiewicz (2000) On the Spanish inferential construction Ser que. International Journal of Pragmatics 10.3: 301-322.

Delahunty, Gerald, and Maura Velazquez-Castillo (2002) The $X$ is that $S$ : A lexico-grammatical device for local discourse management. In James F. Lee, Kimberly L. Geeslin, and J. Clancy Clements (eds.), Structure, meaning, and acquisition in Spanish: Papers from the $4^{\text {th }}$ Hispanic linguistics symposium. Somerville, MA: Cascadilla Press, pp. 46-64.

Francis, Gill (1994) Labelling discourse: An aspect of nominal-group lexical cohesion. In Malcolm Coulthard (ed.), Advances in written text analysis. London: Routledge, pp. 83-101.

Fraser, Bruce (2005) Toward a theory of discourse markers. http://people.bu.edu/bfraser/ (accessed 4 June 2011).

Günthner, Susanne (2012) $N$ be that-constructions in everyday German conversations: A reanalysis of 'die Sache ist/das Ding ist' ('the thing is')-clauses as projector phrases. In Ritva Laury, and Ryoko Suzuki (eds.), Subordination in conversation. Amsterdam/Philadelphia: John Benjamins Publishing Company.

Halliday, M.A.K., and Ruqaiya Hasan (1976) Cohesion in English. London: Longman.

Higgins, F.R. (1976) The pseudo-cleft construction in English. Indiana University Linguistics Club.

Hopper, Paul, and Sandra A. Thompson (2008) Projectability and clause combining in interaction. In Ritva Laury (ed.), Crosslinguistic studies of clause combining: The multifunctionality of conjunctions. Amsterdam: John Benjamins Publishing Company, pp. 99-123.

Huddleston, Rodney, and Geoffrey K. Pullum (2002) The Cambridge grammar of the English language. Cambridge, UK: Cambridge University Press.

Lambrecht, Knud (1994) Information structure and sentence form: Topic, focus and the mental representations of discourse referents (Cambridge Studies in Linguistics 71). Cambridge, UK: Cambridge University Press.

Lerner, Gene H. (2004) Conversation analysis: Studies from the first generation. Amsterdam: John Benjamins Publishing Company.

Levinson, Stephen C. (1983) Pragmatics. Cambridge, UK: Cambridge University Press.

Lewis, David (2004) [1979] Scorekeeping in a language game. In Steven Davis and Brendan S. Gillon (eds.), Semantics: A reader. Oxford, UK: Oxford University Press, pp. 803-816.

Lyons, Christopher (1999) Definiteness. Cambridge, UK: Cambridge University Press.

Massam, Diane (1999) Thing is constructions: The thing is, is what's the right analysis? English Language and Linguistics 3.2: 335-352.

McConvell, Patrick (1988) To be or double be? Current changes in the English copula. Australian Journal of Linguistics 8: 287-305.

Mikkelsen, Line (2005) Copular clauses: Specification, predication, and equation. Amsterdam: John Benjamins Publishing Company.

Miller, Jim, and Regina Weinert (1998) Spontaneous spoken language: Syntax and discourse. Oxford, UK: Clarendon Press. 
Prince, Ellen (1978) A comparison of wh-clefts and it-clefts in discourse. Language 54: 883-906.

Pusch, Claus (2003) Die es que/c'est que-Konstruktion und ihre kommunikativen Dimensionen. In G. Held (ed.), Partikelen und Höflichkeit. Frankfurt: Peter Lang, pp. 295-317.

Pusch, Claus (2006) Marqueurs discursifs et subordination syntaxique: La construction inférentielle en français et dans d'autres langues romanes. In M. Drescher, and B. Frank-Job (eds.), Les marqueurs discursifs dans les langues Romanes: Approches théoriques et méthodologiques. Frankfurt: Peter Lang, pp. 173-188.

Pusch, Claus (2007) Propositional pragmatic markers in Romance: Do they structure discourse or comment on it? Paper presented at International Pragmatics Association conference, Gothenburg, Sweden, July 12, 2007.

Rankin, Ian (1997) Black and blue. New York: St. Martin’s Press.

Rankin, Ian (2000) Set in darkness. New York: St. Martin’s Press.

Rankin, Ian (2003) A question of blood. Boston, MA: Little Brown and Co.

Rankin, Ian (2004) Resurrection men. Boston, MA: Little Brown and Co.

Rankin, Ian (2005) Fleshmarket alley. New York: Time Warner.

Schmid, Hans-Jörg (2000) English abstract nouns as conceptual shells: From corpus to cognition. Berlin: Mouton de Gruyter.

Sirr, Peter (2009) The thing is. In The thing is. Loughcrew, Ireland: The Gallery Press.

Sperber, Dan, and Deirdre Wilson (1995) Relevance: Communication and cognition. $2^{\text {nd }}$ Edition. Oxford, UK: Blackwell.

Terasaki, Alene Kiku (2004) [1976] Pre-announcement sequences in conversation. In Gene H. Lerner (ed.), Conversation analysis: Studies from the first generation. Amsterdam: John Benjamins Publishing Company, pp. 171-224.

Tuggy, David (1996) The thing is is that people talk that way. The question is is Why? In E.H. Casad (ed.), Cognitive linguistics in the redwoods: The expansion of a new paradigm in linguistics. Berlin: Mouton de Gruyter, pp. 713-752.

GERALD DELAHUNTY is Assistant Chair and Associate Professor of Linguistics and English in the English Department at Colorado State University. He has taught at the University of California at Irvine and at San Diego State University. He received his Ph.D. in Social Sciences from the University of California, Irvine and has published on syntactic theory, English syntax, the pragmatics and discourse functions of several non-canonical structures, sociolinguistics, and Irish archaeology. He is author of The English Language: From Sound to Sense (with James Garvey), (Parlor Press/WAC Clearinghouse, 2010, http://wac.colostate.edu/books/sound/).

Address: 359 Eddy Hall, Department of English, Colorado State University, Fort Collins, CO 805231773, United States. Tel.: 1-970-491-1108; e-mail: gerald.delahunty@ colostate.edu 